\section{Intraspecific Polyploidy and Evolution of Diverse Morphological Forms in Convolvulus pluricaulis Chois.}

Convolvulus pluricaulis Chois. is a prostrate, spreading, perennial, wild herb commonly found on sandy or rocky ground under xerophytic conditions in northern India. The species is marked by great morphological variability especially in size of the flower. Our cytological studies indicated the existence of intraspecific polyploidy in the species. The present investigation was, therefore, undertaken to study the possible relationship between cytological and morphological forms of the species.

The haploid chromosome number of $C$. pluricaulis with small flowers was determined as nine. Singh ${ }^{3}$ reported $n=10$ for the same species. Our observations along with those of $\mathrm{Singh}^{3}$ thus indicate the presence of two cytological types in $C$. pluricaulis. Meiotic studies in the large-flowered form revealed it to be a tetraploid with $n=18$. The presence of eighteen bivalents in 50 per cent of pollen mother cells suggests it to be an allotetraploid. The fact that the remaining 50 per cent of cells showed multivalent associations indicates an autotetraploid or a segmental polyploid origin.

As true allopolyploid forms usually do not show multivalent associations, the tetraploid in $C$. pluricaulis may be considered as an autopolyploid or a segmental polyploid. The general morphological gigantism shown by the tetraploid is an additional support for it to be regarded as an auto-or a segmental-polyploid.

The existence of a natural polyploid series has not so far been recorded in any other species of Convolvulus.

Duthie ${ }^{1}$ and Hooker ${ }^{2}$ have described Convolvulus pluricaulis var. macra as a large, densely hairy plant with large flowers. The morphological description of macra ${ }^{1,2}$ is identical with the tetraploid studied in the present investigation. The fact that this variety has been seen to possess double the chromosome number of the small-flowered type further supports the claim of the large-flowered form to be given the rank of a variety. Intraspecific polyploidy has thus played an important part in the evolution of diverse morphological forms in $C$. pluricaulis. The variety macra is commonly found in Punjab and Delhi plains and up to an altitude of $3,000 \mathrm{ft}$. in Kashmir. The small-flowered form which represents the diploid condition is very rare at high altitudes. The distribution of the largeflowered variety is quite in conformity with the general concept that polyploids are found to be more tolerant to extreme ecological conditions than are their diploid relatives.

\section{S. L. TANDON}

C. P. MzaliK*

\footnotetext{
Department of Botany,

University of Delhi,

Delhi 8, India. June 16.

* Lecturer in Botany, Deshbandhu College, Delhi 19.

${ }^{1}$ Duthie, J. F., "Flora of the Upper Gangetic Plain and of the adjacent Siwalik and Sub-Himalayan Tracts" Superintendent, Government Printing, Calcutta, 1911)

${ }^{2}$ Hooker, J. D., "The Flora of British India" (L. Reeve \& Co., Ltd.,

singh, B., Curr. Sci., 20, 105 (1951).
}

\section{SOCIAL SCIENCES}

\section{Main Stages of Social Evolution in Man}

Prof. Grahame Clark has given tentative estimates of the population of England and Wales, or Britain, in early times. These figures, together with the somewhat firmer estimates for the historical period $^{1}$ form the basis of Figs. 1 and 3. L. S. Palmer gives tentative estimates of the number of general kinds of materials used for making things ${ }^{2}$. These form the basis of Figs. 2 and 4.

The difficulties of attempting to quantify states of cultural development are well known. But of the graphs below, we may say, in the words of Stuart Piggott in another connexion (ref. 3 and personal communication, 1959), "While obviously open to criticism in detail at almost every point, it is felt that the broad pattern is sound, and that some sort of graphic statement, however tentative, must be attempted ..." Whereas the slopes of these curves are liable to revision in the light of future knowledge, it is probable that the main 'kinks' are real, which for the present purpose is what matters. It is hoped that a small group of specialists may soon give this topic the attention which it seems to deserve.

The 600,000 or so years of the existence of toolmaking man are occupied, at the zoological level, by a number of different species. But at the sociologieal level there are, perhaps, two or three main stages of social evolution which may be generally recognized.

Figs. 1 and 2 suggest a division into a long and relatively static stage, followed by a short stage of rapid change. By replotting on a larger scale, however, the beginning of the recent upsurge can be traced back to the introduction to Britain of agri-

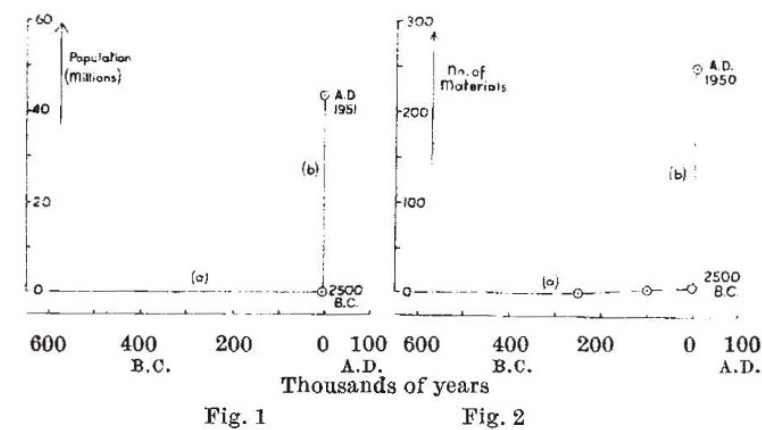

Fig. 1. Plot of population of England and Wales, against time ; stage $(a)$ after Clark (ref. 1). On this scale, the population during stage $(a)$ is indistinguishable from the zero level

Fig. 2. Plot of estimated number of general kinds of materials used for making things, against time; after Palmer (ref. 2). During earliest times and ice ages, the level for populated areas replaces that for Britain

culture and the neolithic way of life. This probably occurred about 2,500 B.c. ${ }^{3}$. Just before that, the total population of Great Britain may have been of the order of 4,500 , with rather more than 3,000 people in England and Wales'. The 'number of materials', sensu Palmer, may have been about 11 .

This primary division is, in fact, into $(a)$ the foodgathering stage, and $(b)$ the food-producing stage ${ }^{4}$. 